\title{
Rico Lins e a Ressignificação da Imagem Gráfica
}

Daniela Souto Resing - UDESC

\section{Resumo}

A premiada exposição "Rico Lins - Uma Gráfica de Fronteira" abre espaço para uma discussão sobre antigas relações entre arte e design. Os trabalhos da mostra permitem uma reflexão sobre o percurso de mais de 30 anos desse designer que prefere atravessar fronteiras a não o fazê-lo. Rico Lins opera de forma anacrônica usando a colagem de imagens aparentemente dissociadas no tempo e constrói ou desconstrói conceitos a partir delas. Rico cria deslocamentos de signos e ícones da história da arte e do design, recontextualizando-os e assim ressignificando as imagens que produz. Ele ainda deixa espaço para que o leitor possa contribuir com esse processo usando seu repertório próprio para apreender suas mensagens e permite que artistas e designers possam repensar os caminhos futuros de suas práticas e teorias.

Palavras-chave

Rico Lins, Colagem, Arte, Design

\section{Introdução}

Pensar as dinâmicas existentes entre as artes visuais e o design gráfico requer abordar como aconteceu o estabelecimento de fronteiras no processo de busca pela autonomia e institucionalização dessas duas áreas, e ainda deve-se observar como o sujeito contemporâneo lida com elas seu contexto sociocultural. Entender como se dão essas dinâmicas ao longo do século $X X$ e como ela acontece hoje pode contribuir para uma ampliação de conceitos e processos criativos. Um levantamento histórico nas duas áreas pode mostrar como os artistas e designers se relacionaram entre si e com suas atividades específicas. Com essa investigação sobre onde e quando as aproximações e distanciamentos entre essas áreas e profissionais acontecem, e o que acontece no atrito entre as diferenças, é possível também repensar os caminhos futuros dessas áreas de conhecimento. 
Visando compreender a complexidade do contexto contemporâneo do design e da arte, além de encontrar oportunidades de aberturas e ampliações de teorias, processos, métodos e conceitos para ambas as partes, este estudo analisa a obra de um designer gráfico brasileiro, atuante e reconhecido internacionalmente, o carioca radicado em São Paulo, Rico Lins. No ano de 2009, este ele realiza a mostra “"Rico Lins - Uma Gráfica de Fronteira", na Caixa Cultural do Rio de Janeiro, exibindo mais de 100 peças de um trajeto profissional de 30 anos. Ao identificar as características dos seus procedimentos e dos resultados obtidos por Rico, podemos observar um exemplo de como o sujeito contemporâneo lida com as adversidades e imprevistos das suas condições de atuação diante do mundo.

Em Rico Lins o design converte-se em trespassamento de estruturas de pensamento e de técnicas produtivas: a comprovação de que o atrito produz energia, o mesmo tipo de energia que se desprende da vida das nossas cidades, dos seus muros e espaços crespos. Por tudo isso é que "Rico Lins - Uma gráfica de fronteira" não é uma mostra no sentido convencional, não se reduz a uma apresentação de seu magnífico portfólio. Mais do que isso, tem-se aqui um artista que traz a público a seiva de sua poética, a explicitação em estado mais puro dos processos e elementos dos quais se vale. Daí o caráter ambiental dessa mostra, uma sorte de "instalação" que esclarece a visão de mundo de Rico Lins, própria a um designer gráfico capaz de fundir, combinar e reciclar palavras, imagens e ritmos, encarnando-os em tecidos, papéis e edifícios, sons e projeções e até mesmo em suportes que rondam a imaterialidade. (FARIAS, 2009, p. 11)

O trabalho desse designer existe na fronteira com a arte, suas referências, sua formação, seus valores e conceitos estão fundamentados profundamente nos mais variados "ícones" da história da arte, como Kurt Schwitters, Andy Warhol, Alfredo Volpi. Apropriando-se dos conceitos abordados por estes e outros artistas, Rico desloca esses conceitos para outros contextos, misturando e combinando linguagens, técnicas, formas conhecidas e criando um processo particular.

Do ponto de vista criativo, sempre me intrigou a ideia do design gráfico como "obra única reproduzida em série". Tal proposta revela a ambiguidade central do trabalho de criação gráfica, sua efemeridade, sua existência limitada por sua condição essencialmente utilitária, reprodutível e descartável. Por outro lado, ela funciona também como um termômetro permanente de seu tempo. De algum modo, sempre esteve presente em 
parte de meu trabalho a apropriação de clichês visuais, seja reutilizando ícones da cultura de massa, seja extraindo referências de obras de artes plásticas ou pelo mero reaproveitamento de materiais impressos industrialmente. Das fotomontagens construtivistas de Rodchenko à banana pop de Andy Warhol, de Kurt Schwitters a Walt Disney, o universo visual contemporâneo é o da cultura de massa e seus produtos: recortes de revistas, tickets, dinheiro, embalagens, santinhos, rótulos, folhetos de cordel, bulas, formulários, propaganda, e a imensa produção de lixo decorrente. (LINS, 2010, p.12)

A exposição percorreu seis grandes capitais de quatro das cinco regiões brasileiras, recebeu reconhecimento do público em geral, e foi premiada por importantes instituições nacionais, por isso sua relevância para a presente discussão é fundamental. Esta mostra traz à luz peças que aproximam a arte do design, nelas as práticas e a história da arte potencializam os aspectos simbólicos e comunicativos do design, conferindo a elas um maior impacto e estímulo à sua leitura. Elas se diferenciam da produção vazia do design sem referências, e do design pasteurizado pelos manuais, cânones e metodologias modernas, ainda vigentes nas instituições de ensino superior de design do Brasil contemporâneo.

Todos nós - pessoas, instituições, empresas - estamos vivendo hoje, de alguma forma, a necessidade de combinar uma compreensão ampla do mundo a uma atuação que parte de um olhar e de um sentimento nascidos do local em que vivemos, da nossa história particular. Isso que hoje é um atributo da contemporaneidade Rico Lins já vem trazendo ao campo do design gráfico há algumas décadas.

Trafegar entre culturas diferentes sem abrir mão da sua própria, trazer ao design gráfico uma forte dose de criação pessoal, beber no caos das ruas e do popular para escrever o erudito, prever e incentivar a interação com o usuário do seu projeto, recorrer à manualidade da tradição brasileira para compor o digital são práticas incensadas em nossa época que Rico aporta desde o início de sua caminhada. (BORGES, 2009, p. 12) ${ }^{1}$

Rico Lins proporciona com seu trabalho a abertura a múltiplas possibilidades de experimentação, movimenta a criatividade e reinventa tanto a produção como todo o

\footnotetext{
${ }^{1}$ BORGES, Adélia. Territórios reinventados. In: FARIAS, Agnaldo (et al). Rico Lins: uma gráfica de fronteira. Rio de Janeiro: Solisluna Editora, 2009.
} 
sistema da arte e do design. Em "Uma Gráfica de Fronteira" essas duas áreas se encontram, e dividindo o mesmo espaço e acontecendo ao mesmo tempo, convidam o público a fazer relações entre suas linguagens, e a perceber os valores intrínsecos de cada peça. A exposição modifica conceitos e nos faz repensar limites e relações instituídas, e traçar paralelos, imaginando realidades possíveis.

\section{"Rico Lins - Uma Gráfica de Fronteira"}

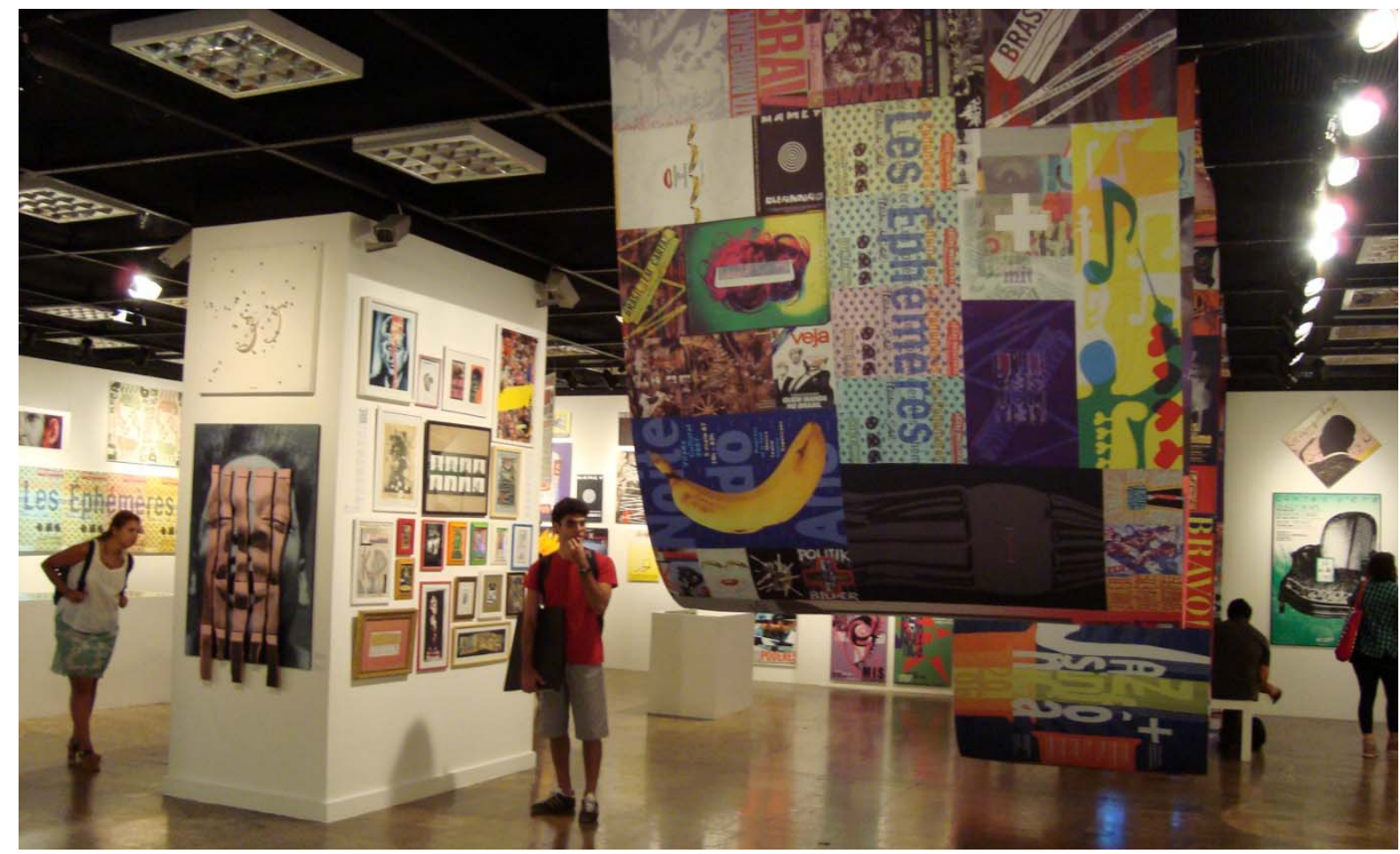

Figura 1: "Rico Lins - Uma Gráfica de Fronteira", exposição itinerante que em 2009 mostra o trajeto gráfico de Rico.

A exposição itinerante "Rico Lins - Uma Gráfica de Fronteira" aconteceu em primeira mão entre fevereiro e março de 2009, na Galeria 1 da CAIXA Cultural do Rio de Janeiro, passou também por São Paulo, Curitiba, Brasília, Recife, Fortaleza. Em seu percurso conquistou o prêmio de Melhor Obra Gráfica de 2009, na categoria Artes Visuais, pela Associação Paulista dos Críticos de Arte (APCA), e o catálogo da exposição levou o Prêmio Jabuti 2010, na categoria Design Gráfico. O reconhecimento institucional do trabalho de Rico reforça o fato de que sua produção merece um olhar a mais, uma reflexão, um debate. O público dessa exposição, assim como o próprio artista, pôde rever e repensar a obra de mais de 30 anos do 
designer, representada por 100 peças gráficas selecionadas pelo curador Agnaldo Farias.

No texto de abertura do catálogo, Farias menciona que a obra de Rico mostra "como são imprecisos os limites entre a arte e o design. Mais ainda: arte e vida." (FARIAS, 2009 , p. 8) A seguir ele esclarece que está falando não apenas de artes plásticas ou visuais, mas da arte no seu sentido mais amplo, que incluiria arquitetura, moda, música, dança, poesia. Farias também argumenta que os limites e fronteiras entre essas áreas são forjados nas academias, para separá-las das formas populares de arte, que para ele, nascem de "inteligências tão potentes que, como é frequente em nosso país, vingam em territórios inóspitos, áridos e violentos." (FARIAS, 2009, p. 8)

Nunca me aventurei a definir ou a traçar uma fronteira para o que é o design. Isso nunca fez parte do meu universo de preocupações, seja do ponto de vista da atividade profissional, do espaço expressivo ou da minha própria formação. Fui conduzido a esse universo da imagem que se chama design por meu interesse pela comunicação, por um lado, e pela visualidade, por outro. Ambas sempre me atraíram muito e descobri casualmente que elas se combinavam numa disciplina chamada Comunicação Visual, ensinada numa escola chamada ESDI [Escola Superior de Desenho Industrial].

Assim, entrei para a ESDI e ali havia uma coisa chamada design, com a qual comecei a trabalhar. Quando percebi que gostava de design já era tarde demais. Por isso, essa fronteira para mim nunca foi muito clara e definida, mas muito flexível. Gosto muito de brincar com o exercício de contaminação dessas áreas. O processo criativo reside no binômio da liberdade e do limite. Ter um limite muito bem definido é ter um muro para pular. É um exercício de liberdade criativa seja com as formas, com a tipografia ou com os processos metodológicos, no qual você consegue ter uma amplitude um pouco mais divertida.

Nesse sentido, nunca fui muito fiel ao design no sentido tradicional, linear, apesar de ter uma postura de comunicar para responder a uma demanda muito clara, que é uma atitude do design, mas talvez por caminhos que não sejam exclusivos da disciplina. ${ }^{2}$ (FARIAS, 2009, p. 16)

\footnotetext{
${ }^{2}$ Entrevista de Rico Lins a André Stolarski, publicada no catálogo da exposição.
} 
Para Rico Lins a expressão "arte gráfica" é a que melhor define seu trabalho. Uma formação híbrida define sua atuação profissional e o próprio trabalho em si. Rico conhece bem as diferenças entre arte e design e por isso mesmo ele identifica em seus procedimentos operacionais, em sua fatura, especificidades ora de uma área, ora de outra. O trabalho de Rico Lins parece muito com o próprio desenvolvimento do design no Brasil. Formado em design pela ESDI, no ano de 1976, no Rio de Janeiro, ele fez sua especialização na Université de Paris VIII, em 1981 e em 1987 ele obtém o título de Master of Art, pelo Royal College of Art de Londres. Além disso, ele passou pela Holanda, Alemanha, Espanha e Estados Unidos, conviveu com pessoas de várias cidades do mundo e construiu assim uma personalidade bastante cosmopolita, tão híbrida quanto seu trabalho.

\section{A formação de Rico e do Design no Brasil}

Por muito tempo as artes visuais e o design gráfico caminharam lado a lado. Antes de o design se institucionalizar, a atividade já existia, mas era realizada por artistas, arquitetos, entre outros profissionais. Philip Meggs remonta a história do design às pinturas das cavernas de Lascaux, assim como os primeiros historiadores da arte já o faziam também nesse campo. Pensando esse trajeto percorrido pela arte e pelo design a partir de uma sucessão de fatos que oficializaram o uso do termo design, as atividades relacionadas a ele e, sua institucionalização e autonomia com relação à arte, podemos perceber a alternância aproximações e distanciamentos entre essas duas áreas do conhecimento ao longo do tempo.

Chico Homem de Melo, no livro "Linha do tempo do design gráfico no Brasil" mostra que atividades relacionadas com o que hoje entendemos por design gráfico iniciaram no país com a criação da Impressão Régia, em 1808. No século XIX as tipografias particulares também começam a surgir, e o mercado editorial se desenvolve. Rafael Cardoso, PhD em história da arte pelo Courtauld Institute of Art de Londres, afirma em seu livro "O design brasileiro antes do design: aspectos da história gráfica, 1870-1960" que a Academia Imperial de Belas Artes do Brasil passou a ministrar a disciplina de desenho industrial na década de 1850. Na sequência, a Semana de Arte Moderna de 1922 atinge profundamente a produção do design. Em 1948 é criado o Museu de Arte Moderna do Rio de Janeiro (MAM/RJ) 
e o Museu de Artes de São Paulo (MASP), em 1950 é inaugurado no MASP o Instituto de Arte Contemporânea (IAC), com uma exposição de Max Bill. No ano seguinte acontece a $1^{\text {a }}$ Bienal de Arte de São Paulo, e na mesma década é aberto o primeiro escritório de design modernista, o Forminform, integrado por Geral de Barros, Alexandre Wollner, Ruben Martins e Walter Macedo. Em 1959 o MAM/RJ realiza uma conferência com Tomás Maldonado e Otl Aicher, professores da Escola de Ulm. Todos esses acontecimentos levam a criação da Escola Superior de Desenho Industrial (ESDI), em 1963, onde Rico Lins se forma no ano de 1976.

A ESDI vinha de uma relação direta com a Escola de Ulm, pautada na exacerbação do racionalismo proveniente da arte construtiva e do funcionalismo. Aloisio Magalhães, Décio Pignatari, Karl-Heinz Bergmüller e Zuenir Ventura eram professores da ESDI nessa época e já assinalavam as divergências de pensamentos na institucionalização do design. A Ulm era a sucessora da Bauhaus, que ao contrário da escola que fundava o design brasileiro, propunha um ensino mais abrangente, baseado no intercâmbio de linguagens. Enquanto aqui seguíamos a Ulm, influenciados pela conferência de Tomás Maldonado no MAM mencionada anteriormente, nos Estados Unidos eram os ensinamentos da Bauhaus que eram disseminados por Josef Albers, na Mountain College da Carolina do Norte, e por Lázló Moholy-Nagy, na New Bauhaus de Chicago. Ao mesmo tempo no Brasil a contracultura se fortalecia com manifestações de protesto à ditadura vigente e se expandiam para os campos das artes visuais e do design gráfico. No design gráfico Rogério Duarte se destacava com sua linguagem psicodélica e sobreposições de cores vivas nas capas de discos da Tropicália e nos cartazes de filmes do Cinema Novo. Nas artes visuais Hélio Oiticica e os neoconcretos traziam a participação ativa do espectador na criação da obra. A atitude antropofágica se reacendia com Zé Celso Martinez no Teatro Oficina, e com Haroldo de Campos nas reedições de Oswald de Andrade. Era com esse ambiente que Rico Lins iria se deparar no momento da saída de sua graduação.

Apesar da sua pouca idade, quando Rico Lins entendeu que o seu negócio era o design ele já era muitas outras coisas e ainda queria muito mais: lidava e transitava por territórios diversos um cidadão do mundo para o qual a nacionalidade, mais que um limite, era uma falsa questão, e o intercâmbio de ideias, o contrabando de tempos e espaços, uma condição para se 
sobreviver num mundo, para o bem e para o mal, definitivamente contaminado. Afinal, quais são mesmo as fronteiras da língua? E da visualidade? Quem gosta da imagem, que tem a voluptuosidade da imagem, parafraseando Pedro Nava em sua defesa da palavra, interessa-se por tudo que há, seja aquilo que provém do outro ou aquilo que, sob a forma de erro, provém de mim mesmo, um mim oculto, incerto. Um objet trouvé encontrado à tona da escuridão mais íntima. (FARIAS, 2009, p. 10)

Rico comenta em entrevista a André Stolarski no catálogo da exposição que sentia mais afinidade com a Bauhaus do que com a UIm, pois a primeira representava um pensamento mais próximo do trabalho que ele realizava, cruzando ideias e nutrindo um diálogo ente design, arte, arquitetura, fotografia, moda, poesia, entre design e sociedade. Ele conhece as fronteiras entre a arte e o design, mas em seu trabalho atravessa essas fronteiras na intenção de alimentar uma cultura do design, ele procura despertar as discussões entorno desse ofício que hoje se depara com um mundo cada vez mais invadido por imagens em excesso. Incomodado com um cenário cheio de imagens vazias, Rico quer dar significado às suas imagens, ele se preocupa com o conteúdo por trás da forma.

Atualmente, uma palavra vale mais do que mil imagens. As imagens estão absolutamente desprovidas de conteúdo. Estamos vivendo um momento em que é necessário um trabalho de ressignificação das imagens. Temos acesso a imagens o tempo inteiro e elas estão cada vez mais vazias e desconectadas de seu conteúdo. Se você não tem a capacidade de atribuir conteúdo a uma imagem, então ele não existe. ${ }^{3}$ (FARIAS, 2009, p. 24)

As referências artísticas são a base para a ação de ressignificação das imagens no design de Rico Lins. Desde a infância, ele teve o incentivo ao contato com grandes artistas plásticos brasileiros, seja através da ampla biblioteca de livros ilustrados do avô ou das visitas com o tio aos ateliês de artistas como Volpi, Djanira e João Câmara. Em suas passagens pela Europa e pelos Estados Unidos, Rico ampliou e diversificou seu repertório, que foi ficando cada vez mais eclético. Sempre procurando exercitar sua liberdade criativa, ele se manteve aberto às influências externas, mas nunca deixou de filtrá-las com sua lente. Rico dá prioridade ao

\footnotetext{
${ }^{3}$ Entrevista de Rico Lins a André Stolarski, publicada no catálogo da exposição.
} 
conceito a ser abordado em cada projeto e a partir desse conceito é que ele define as formas, técnicas, linguagens e referências irá utilizar.

\footnotetext{
Ciente de que cada vez mais o design é uma colagem, zona de articulação da tecnologia, mercado e cultura, e que cada um desses termos é um conceito pletórico, Rico Lins sempre se pautou pela sobreposição de técnicas e linguagens díspares, da xilogravura e da tipografia mais ortodoxa ao recurso gráfico de última geração; do lambe-lambe à informação processada digitalmente; daquilo que é aplicado com apuro ao que se obtém arrancando. A colagem garante ao trabalho gráfico um resultado mais próximo dos processos operacionais e da imagética própria à cultura contemporânea que da experiência visual controlada e que era oferecida pelos modernos. Um jogo de justaposições entre vozes e ruídos; uma área de tensão em que formas e figuras mantêm-se num equilíbrio precário, crispado, ambíguo, que é, afinal das contas, o responsável por demandar inteligência àquele que se põe a lê-la. Em Rico Lins o design converte-se em trespassamento de estruturas de pensamento e de técnicas produtivas: a comprovação de que o atrito produz energia, 0 mesmo tipo de energia que se desprende da vida das nossas cidades, dos seus muros e espaços crespos. (FARIAS, 2009, p. 7)
}

Seu repertório não comporta restrições quanto a origens geográficas ou sociais, global/local, erudito/popular não são critérios limitadores, mas sim binômios constantes em sua trajetória. Rico usa todas as linguagens e técnicas que forem necessárias para ajudá-lo a criar suas mensagens e chamar a atenção de seu o público. Do Construtivismo, passando pela Pop Arte e pelo Dadá, ele faz da colagem sua principal ferramenta de trabalho e pensamento, como veremos a seguir em peças selecionadas a partir da sua grande exposição de 2009 .

\section{Rico e as "construções" de Rodchenko}

As capas da revista acadêmica alemã Kultur Revolution foram suporte para o trabalho de Rico Lins desde sua primeira edição, em 1982. Com um a postura esquerdista, a publicação teve suas capas marcadas por um experimentalismo constante, o que condizia com a diversidade temática trazida por seus artigos. Ciente do perfil de seu público e da capacidade de clara apreensão das mensagens 
das capas, Rico buscou realizar um trabalho que brincasse com o conhecimento do leitor.

Na capa "O Discurso Faz a Hegemonia", Rico Lins recupera em seu repertório elementos do Construtivismo Russo de Rodchenko, e faz uma crítica ao discurso alternante da esquerda e à ascensão da socialdemocracia alemã. Usando a técnica da colagem para criar um personagem que mistura uma tipografia com formas emprestadas do alfabeto russo, a careca e olhos de Foucault com a barda de Marx, a estrela de Mao-Tsé Tung na testa e um bottom de Trótski no ombro. As capas da Kultur Revolution eram impressas em três cores. Rico acompanhava o desenvolvimento prático do processo analógico (em off set) na gráfica alemã responsável pela produção da revista. Isso lhe permitia experimentar as possibilidades de sobreposição das camadas de cores, e por vezes ampliar a capacidade de lidar com resultados inesperado. capacidade de lidar com resultados inesperado.
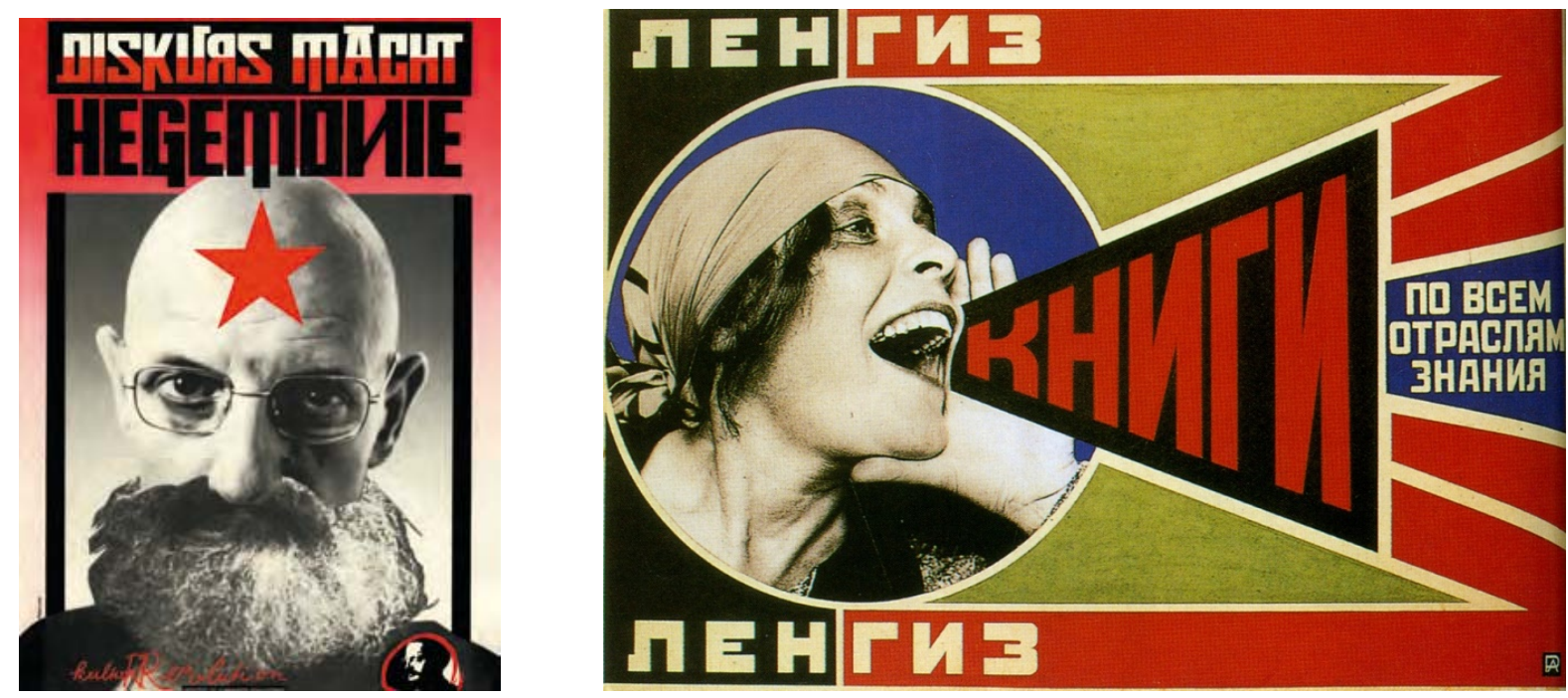

Figura 2: "O Discurso Faz a Hegemonia", capa da Kultur Revolution, por Rico Lins, 1986.

Figura 3: Cartaz do Construtivismo russo, de Alexander Rodchenko, 1924. 
A única coisa que podia fazer era tentar usar esse espaço para me divertir e realizar um trabalho que pudesse atingir o público de forma inteligente, que me permitisse experimentar com a linguagem visual, que enviasse mensagens atravessadas e inesperadas. [...] A revista deveria ter vários capistas, mas eu era o único. Precisava fazer várias capas e renovar a publicação a cada número, com temas diferentes, pelos quais precisava trafegar. [...] Pegava fontes do construtivismo alemão, me inspirava nos passos de tango para falar sobre a esquerda ou numa colagem do Bayer para falar sobre a presença da imigração turca na Alemanha. Eu experimentava graficamente, mas todas as capas eram bem-recebidas porque o público tinha um olhar preparado para isso. Nesse sentido, a comunicação era muito clara. ${ }^{4}$ (FARIAS, 2009, p. 20)

Na busca por uma construção baseada em fundamentos racionais, o Construtivismo que a ESDI ensinava passou por várias fases e teve muitas vertentes. Iniciando na Rússia do início do século XX esse movimento artístico nasce numa sociedade voltada para a vida política ativa, em que a arte deveria ter função de construir uma realidade fundada em uma ideologia revolucionária. Segundo Argan, dessa forma os artistas desse movimento buscavam popularizar a arte e transformar as cidades do futuro em lugares onde "sujeitos" e "objetos" se aproximam. Argan comenta que Malevitch, artista russo que encabeçava o Suprematismo (movimento paralelo ao Construtivismo na vanguarda russa), acreditava que a verdadeira revolução não iria substituir uma noção de mundo decadente por uma nova, mas iria sim destituir o mundo "de objetos, noções, passado e futuro, uma transformação radical em que o objeto e o sujeito são igualmente reduzidos ao 'grau zero'." (ARGAN, 1992, p. 325) Tatlin, um dos idealizadores do Construtivismo, compartilha de algumas ideias de Malevich, porém discorda dele na questão política, pois acredita que a arte, assim como a arquitetura, é uma "construção" e não uma "representação" e por isso deve ser visual e funcional ao mesmo tempo, potencializando assim a criatividade e a inventividade na revolução.

\footnotetext{
${ }^{4}$ Entrevista de Rico Lins a André Stolarski, publicada no catálogo da exposição.
} 
Como artistas, tanto A. RODCHENKO (1891-1956), o teórico marxista do Construtivismo, como EL LISSITZKY, o artista gráfico para quem a teoria da forma é teoria da comunicação visual, dão grande importância ao rigorismo formal suprematista; no plano da ação cultural-política, porém querem demonstrar que, num sistema onde a indústria não está vinculada à superestrutura capitalista, não pode subsistir nenhuma contradição entre a operação estética e a tecnologia industrial. As técnicas industriais não só abriram possibilidades ilimitadas à interatividade dos artistas, como também construíram um aparato funcional por meio do qual o impulso criativo da arte entrará no círculo da vida social e, reciprocamente, a sociedade estimulará a criatividade da produção. (ARGAN, 1992, pp. 329-330.)

Quando o Construtivismo foi reprimido pelo governo de Stalin, que reduzia a arte a um instrumento puramente político, o movimento se espalhou pela Europa. Chegando à Alemanha, tornou-se a base do pensamento que funda a metodologia didática da Bauhaus. E mais tarde, o Estilo Internacional se afirma como método institucional do design, amplamente praticado na Escola de Ulm e, mais tarde, na ESDI. Em "Linha do tempo do design gráfico no Brasil”, Chico Homem de Melo situa o trabalho de Rico no "pós-modernismo", que segundo o autor, configura a "falência dos grandes discursos totalizantes.", cuja consequência é chamada de "desconstrução", um processo que influencia tanto a arte como o design. (MELO, 2011, p. 546). A fragmentação e a desconstrução foram tônicas recorrentes nas décadas de 1980 e 1990. E Rico se utiliza muito desses dois recursos compositivos em vários de seus trabalhos. Ele recontextualiza as discussões do Construtivismo e joga com as regras que vigoram no establishment do design gráfico, remetendo diretamente ao contexto criativo de Rodchenko, fazendo uma colagem de tempos, teorias e ideologias nessa capa da Kultur Revolution.

\section{Rico e as "combinações" de Rauschenberg}

Em 1989 Rico é convidado pela Cinevista, distribuidora e produtora de Nova lorque, para fazer o cartaz de lançamento do filme "Labirintos de Paixão", de Pedro Almodóvar, no mercado americano. Usando um recurso pensado para vários de seus cartazes, Rico planejou o layout do cartaz de forma que ele causasse um efeito de ampliação visual ao ser colado lado a lado nos muros das cidades. Combinando 
a estética carregada e "kitsch" de Almodóvar com o colorido do cinema indiano (com o qual Rico estava começando a entrar em contato na época), criou uma colagem que diferia bastante do estereótipo do cartaz de cinema americano.
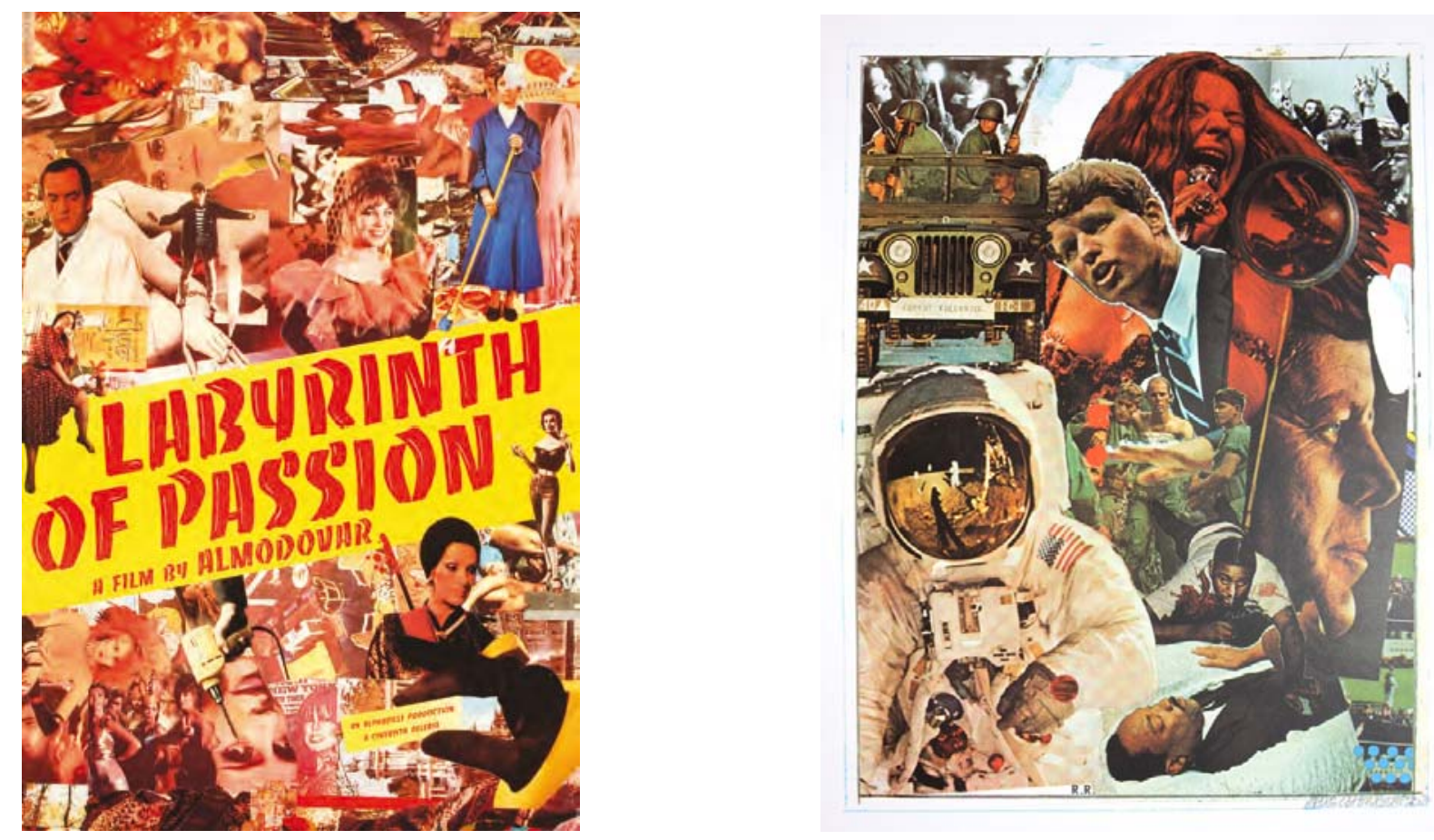

Figura 4: Cartaz do filme Labirinto de Paixão, de Pedro Almodóvar, por Rico Lins, 1989

Figura 5: "Sinais", colagem de Robert Rauschenberg, 1970

A colagem permite que você associe elementos que não necessariamente combinam, que permanecem dissociados. Essa associação gera uma coisa que é mais poderosa do que a soma dos elementos. Isso é evidente também pela capacidade que nós temos de ampliar nosso repertório visual, pela obrigação que temos de passá-lo adiante. Assim como um escritor tem um compromisso com a preservação da língua escrita, nós designers temos um comprometimento com a preservação da cultura visual. Além disso, é importante alimentarmos esse repertório com as referências que as pessoas têm - e elas são inúmeras, vêm de caminhos os mais diversos possíveis, tropeçamos nelas o dia inteiro. $^{5}$

\footnotetext{
${ }^{5}$ Entrevista de Rico Lins a André Stolarski, publicada no catálogo da exposição.
} 


\section{$[\ldots]$}

Eu queria fazer um cartaz com a cara desse filme, cuja estética ia na contramão de todo cinema que víamos. Acabei fazendo uma colagem malfeita de elementos amontoados. Não era possível saber se os cartazes tinham acabado de ser colados na parede ou se estavam sendo arrancados para outros serem colados por cima. Essa relação do espectador com o cartaz é muito importante para a sua visualização. ${ }^{6}$ (FARIAS, 2009, p. 22; 26)

Em meados dos anos 1950, o artista americano Robert Rauschenberg começava a produzir uma série de obras às quais as categorias pintura ou escultura não se encaixavam. Como as obras misturavam características materiais tanto da pintura como da escultura, ele denomina combine painting. Sua pintura estava incorporando elementos da vida real em três dimensões, como cadeiras, escovas de dente, resíduos de objetos já consumidos. O trabalho desse artista também foi chamado de "neo-dadá", pois ele também se inspirava nas colagens de Kurt Schwitters, assim como Rico Lins. Todavia, enquanto Schwitters usava objetos encontrados (object trouvé), tanto Rico como Rauschenberg trabalham com objetos guardados. Argan conta que Rauschenberg guardava objetos dos quais se apropriava para utilizar posteriormente. Ele voltava seu olhar paras as coisas que a sociedade moderna, tão presenteísta e imediatista, descartava, pois na modernidade o passado não tinha mais valor.

\footnotetext{
${ }^{6}$ Idem anterior.
} 
Excluído desse presente, que, ademais, não o interessa, ao artista resta apenas manipular o passado, reutilizar os refugos: salvando-os, salva-se a si mesmo da condição de "refugo" a que é lançado pela sociedade. Não se explicaria sua frequente referência Às obras-primas do passado (ainda que fanadas nas reproduções correntes) sem uma melancólica nostalgia por aquela que foi, ejá não pode mais ser, a profissão do artista. Para ele, não existe uma história que situe as lembranças numa perspectiva clara; essas obras-primas não passam de recordações misturadas, confusas, emaranhadas com muitas outras. No entanto, essas recordações inertes constituem toda sua sutil existência de artista; não pode se separar delas, objetivá-las. Para ele, a arte é a entrada na desordem, na dimensão do indistinto. (ARGAN, 1992, pp. 642-643.)

Da mesma forma, Rico guarda em sua memória referências da sua identidade híbrida, de um brasileiro que viajou pelo mundo, que estudou referências eruditas e populares. De acordo com cada projeto ele busca na arte um ou de outro elemento, formal ou conceitual, para dar sentido às suas peças gráficas. O designer está sempre atento às formas mais diversas de se comunicar com seu público, por isso precisa lidar com o repertório de cada leitor que pretende atingir. Nesse sentido, Rico encontra-se aberto à experimentação, a referências passadas e tendências futuras, sem se prender no tempo nem o espaço, ampliando os territórios do design e perambulando ora para um lado de suas frágeis fronteiras, ora para o outro.

Há quase trinta anos, o trabalho de Rico Lins vem afirmando esse modo aberto de ver e viver: de saltos transversais e possibilidades recombinantes. Um dos primeiros designers brasileiros a se entregar plenamente à fluidez do discurso como princípio criador, seus projetos forçam os limites do próprio design, contaminando a velha noção de pureza das formas com uma renovada hibridez de técnicas, suportes, linguagens. Questionado sobre a relação entre indisciplina e colagem em sua obra, ele provoca: "atrito gera energia". É um princípio básico da física, do mundo das coisas. Em outros tempos, quando ainda se acreditava na objetividade do mundo físico, o design se propunha ao papel de diminuir os atritos, de tornar invisíveis as emendas, de fazer tudo ficar mais fácil. Não mais. Na era da informação, a física é de desenho animado. O piano cai sobre o coiote, mas 
não o mata. O atrito gera fluidez; e facilitar demais as coisas, empobrece. (CARDOSO, 2009, p. 15) ${ }^{7}$

Para enriquecer seu design, Rico opera seu processo produtivo com um senso crítico capaz de lidar com correntes de pensamento e movimentos artísticos antagônicos ou desconexos. Ele cria outros vínculos entre partes longínquas da própria história da arte e do design. De certa forma, ele tem uma atitude iconoclasta, atribuindo outros significados ou deslocando para outros contextos, ícones consagrados tanto da arte como do design. Rico subverte as metodologias e fórmulas prontas, seu olhar transversal lhe permite fazer associações inesperadas, que recuperam elementos esquecidos no passado e ampliam as possibilidades imaginadas para o futuro.

\section{Rico e a "transgressão" de Schwitters}

No ano de 2005 aconteceu a mostra "Brasil em Cartaz", evento integrante das celebrações do Ano Brasil-França. A exposição foi realizada pelo Pôle Graphisme de Chaumont, que convidou Rico Lins para curador, suas atribuições incluíam além de selecionar os trabalhos dos designers brasileiros a serem expostos, criar o cartaz e o catálogo. Rico selecionou cartazes da segunda metade do século aos dias de hoje, do primeiro cartaz da Bienal de São Paulo, de 1951, às contemporâneas produções digitais e intervenções de arte de rua. O primeiro contato de Rico com o cartaz foi através das aulas de gravura no colegial. Na ESDI ele acompanhava os ensinamentos de Aloisio Magalhães e Karl-Heinz Bergmiller. Também teve acesso a metodologia de controle do processo criativo disseminada por Lina Bo e Pietro Bardi no IAC (Instituto de Arte Contemporânea). Mas o foco de Rico se volta mais para a expressão do que para a metodologia do design, um modelo que visava reforçar o processo de industrialização do país. Por isso ele foi buscar inspiração nas manifestações da cultura popular como, por exemplo, a folclórica literatura de cordel, situada do lado oposto ao defendido pela elite do design institucionalizado, livre de cânones e regras racionais.

\footnotetext{
${ }^{7}$ CARDOSO, Rafael. O perfeito é péssimo. In: FARIAS, Agnaldo (et al). Rico Lins: uma gráfica de fronteira. Rio de Janeiro: Solisluna Editora, 2009.
} 

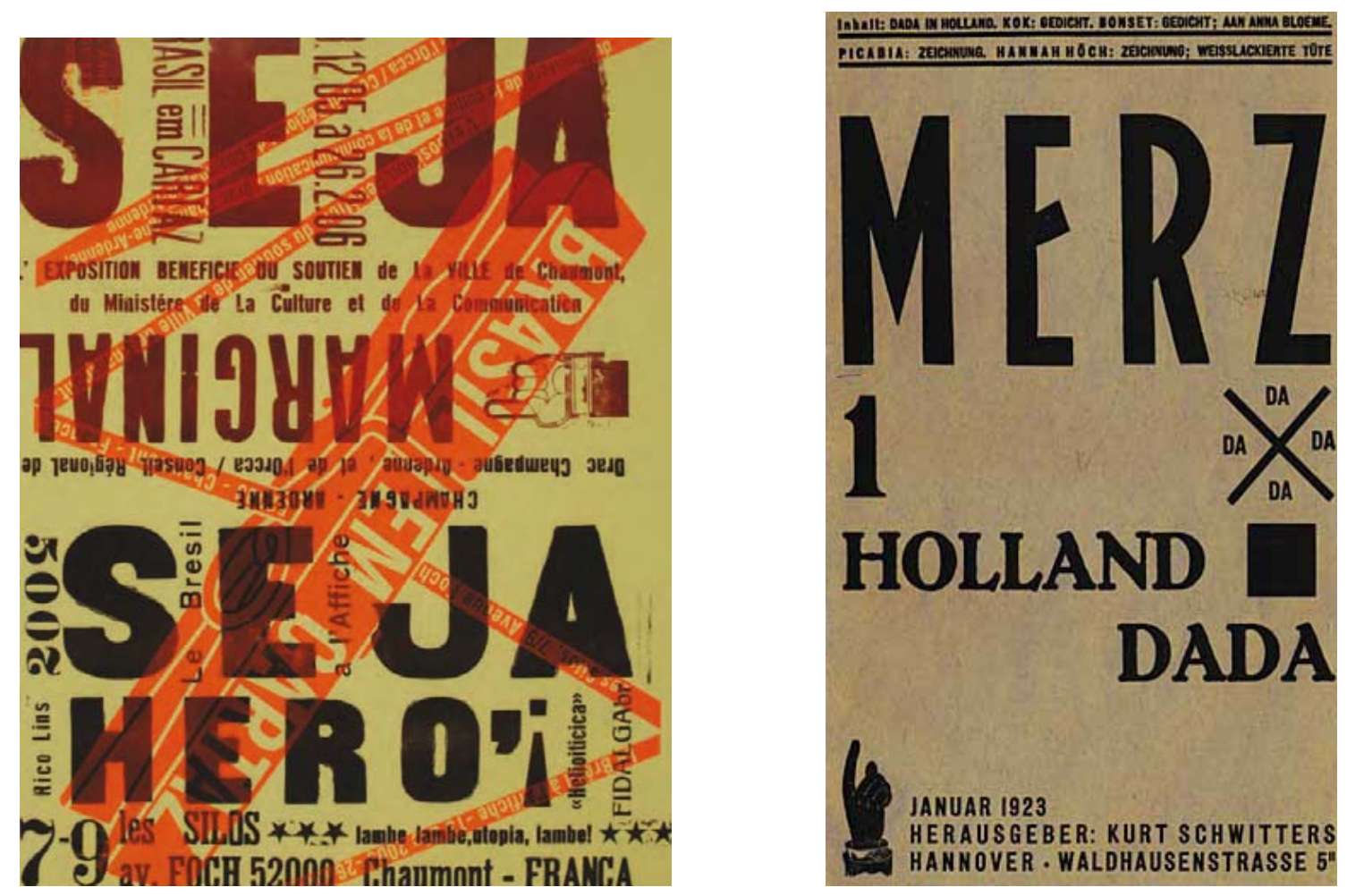

Figura 6: Cartaz da mostra "Brasil em cartaz", por Rico Lins, 2005

Figura 7: Capa da Merz $\mathrm{n}^{0} 1$, editada por Kurt Schwitters, 1923

O primeiro plano desse cartaz em estilo lambe-lambe destaca um elemento fundamental dos cordéis, que eram pendurados em varais, o grampo de roupa. O grampo é sobreposto a uma camada de segundo plano, composta pela frase de Hélio Oiticica "Seja marginal, seja herói!", impressa com tipografias superampliadas, que dão um caráter transgressor ao cartaz e remetem-no diretamente às composições do movimento Dadá. Além das justaposições de formas, tempos, conceitos, ele também sobrepõe processos de impressão, cada camada desse cartaz é feita em um processo diferente. Combinando off set, serigrafia e tipografia, e ainda manipulando as tintas de impressão em boca de máquina, Rico lida com a contribuição do acaso e proporciona uma certa unicidade, pois cada cartaz diferia em algum detalhe do outro. Rico utilizou cores variantes e assim criou uma série que restaura um aspecto mais artístico da produção gráfica. (LINS, 2010, p. 62) 
Kurt Schwitters é uma referência forte para Rico, ele o cita em vários trabalhos. Esse cartaz é mais uma prova dessa identificação. Rico se apropria das formas, símbolos, atitudes e conceitos de Schwitters, único artista dadaísta que se destacou em Hanôver. Argan comenta que o artista foi recusado no clube Dada e assim cria seu próprio espaço com a publicação da Merz, de 1923 a 1932 (ARGAN, 1992, p. 684), que contava com colaboradores como Arp, El Lissitzsky e Theo Van Doesburg (DEMPSEY, 2003, p. 118). Schwitters também foi influenciado pelo cubismo, e a partir de sua leitura dele desenvolveu assemblages ${ }^{8}$ marcantes.

\section{Conclusão}

De forma semelhante ao desenvolvimento do design gráfico contemporâneo, a arte contemporânea desperta questionamentos constantes aos sistemas de institucionalização e historiografia e teorização das suas práticas. A história da arte, por exemplo, está revendo suas metodologias baseada nas pesquisas de Georges Didi-Huberman. Para este estudioso, a relação sujeito-objeto deve ser modificada, a história da arte não deve se prender à linearidade do tempo, para ele a história deve estar aberta à "montagem de tempos anacrônicos" (PUGLIESE, 2005, p.1)

Este autor propõe que a escrita da história da arte seja o sintetizar de uma montagem historiográfica como imagem dialética. A abertura da montagem de tempos anacrônicos possibilitaria a reflexão sobre as bases da consideração do olhar do historiador da arte sobre a imagem, que é diferente do olhar objetivo privilegiado pela iconologia, mas sem cair em uma espécie de relativismo.

O conceito de montagem na historiografia da arte é fundamental na proposta de Didi-Huberman, uma vez que não se concebe a construção dinâmica da história da arte como narrativa, descrição ou análise estrutural de um fenômeno. Esta noção atinge diretamente a base epistemológica da história da arte, interditando a crença na objetividade da história e de qualquer certeza histórica ou interpretativa, além de incorporar positivamente o conceito de anacronismo e de abertura dialética. [...] Longe

\footnotetext{
${ }^{8}$ Assemblages são colagens feitas com a justaposição de objetos tridimensionais. (DEMPSEY, 2003, p. 216).
} 
da grande narrativa, na qual a partir de um ponto de vista ideal o historiador da arte vê o mundo limitado pelo cubo italiano, ele se vê como sujeito portador de uma memória - diante da imagem, e das múltiplas temporalidades que ela comporta simultaneamente. (PUGLIESE, 2005, pp. 1-2)

A teoria que pode balizar novas visões sobre a história da arte se fundamenta em pensadores da disciplina como Warburg e Benjamin, que trabalharam com concepções de "montagem" em seus métodos. Inspirados, por exemplo, nos processos de montagem cinematográfica de Carl Eiseinstein, nas collages de John Heartfield - assim como nos procedimentos de outros artistas que relacionavam seus trabalhos com obras aparentemente distantes no tempo, mas muito próximas ora em forma, ora em conteúdo, ora em ambos os aspectos - esses dois teóricos influenciaram profundamente as pesquisas de Huberman. Segundo Pugliese (PUGLIESE, 2005, p. 1), a ideia dele era que para se compreender a arte contemporânea se deveria partir do objeto empírico em sua construção metodológica e relacioná-lo com outras imagens, guardadas na memória, no repertório do historiador, ou do estudioso da arte.

Pode-se dizer que Rico Lins opera de forma anacrônica. Ele também usa a colagem de imagens aparentemente dissociadas no tempo e constrói ou desconstrói conceitos a partir delas. Rico cria deslocamentos de signos e ícones da história da arte e do design, recontextualizando-os e assim ressignificando as imagens que produz. Além disso, ele deixa espaço para que o leitor possa contribuir com esse processo, colocando seu repertório próprio para interagir na leitura suas mensagens. Seu trabalho fica aberto à leitura do público, aberto às influências, aberto a conceitos relacionados ao design e à arte, ele salta no tempo e busca em imagens da sua memória, aquilo que poderá alimentar sua imaginação e criatividade. Seu pensamento e procedimentos são anacrônicos e por isso podem ajudar a compreender a arte, e aproximar o público do design, criando uma cultura do design, onde se discutem abordagens e em paralelo se projetam possibilidades futuras e paradoxalmente imprevisíveis, mas experimentáveis.

Se formos um pouco menos elitistas - e o olhar não é elitista, ou seja, não elegemos o que vemos, apesar de selecionarmos o que gostamos; vemos o que passa na frente, o público vê o que passa na frente - perceberemos 
que tudo vale: Marcel Duchamp, Kurt Schwitters ou uma colagem no quarto de uma criança, uma coisa pintada na rua, um rótulo, tudo isso faz parte do universo visual que nos permeia. Estamos mergulhados nisso. Nosso trabalho é editar essas imagens e articular esses signos para ajudar a criar um certo repertório, estabelecer uma comunicação visual. É nesse terreno que surrealismo e dadaísmo se misturam, porque estamos falando de símbolos e a linguagem simbólica é sugestiva. Quando você descontextualiza uma coisa como esses movimentos faziam, joga uma luz nova sobre aquilo. Esse trabalho é fundamental. ${ }^{9}$ (FARIAS, 2009, p. 22)

\section{Referências Bibliográficas}

ARGAN, Giulio Carlo. Arte Moderna. Trad. Denise Bottman e Federico Carotti. $10^{\mathrm{a}}$ ed. São Paulo: Companhia das Letras, 1992.

CARDOSO, Rafael (org.). O design brasileiro antes do design: aspectos da história gráfica, 1870-1960. São Paulo: Cosac Naify, 2005.

DEMPSEY, Amy. Estilos, escolas e movimentos. Trad. Carlos Eugênio Marcondes de Moura. $2^{\mathrm{a}}$ ed. São Paulo: Cosac Naify, 2005.

FARIAS, Agnaldo (et al). Rico Lins: uma gráfica de fronteira. Rio de Janeiro: Solisluna Editora, 2009.

LINS, Rico (et. al.). Rico Lins: projetos gráficos comentados. São Paulo: Solisluna Editora, 2010.

MEGGS, Philip B.. História do design gráfico. Trad. Cid Knipel Moreira. São Paulo: Cosac Naify, 2009.

MELO, Chico Homem de (org. e textos) e RAMOS, Elaine. (org. e design). Linha do tempo do design gráfico no Brasil. São Paulo: Cosac Naify, 2011.

PUGLIESE, Vera. O Conceito de Montagem na Obra de Georges DidiHuberman. In: II COMA (COLETIVO DO MESTRADO EM ARTE). Anais eletrônicos. Brasília, DF: Universidade de Brasília (UnB), 2005. Disponível em http://www.geocities.ws/coma arte/2005/artigos.html. Acesso em: 26/07/12.

\footnotetext{
${ }^{9}$ Entrevista de Rico Lins a André Stolarski, publicada no catálogo da exposição.
} 


\section{Referências Imagéticas}

Figura 1 - Disponível em:

http://www.netbureau.com.br/datskat/blog/wp-content/uploads/2009/03/ricolins1.jpg Acesso em: 03/07/12

Figura 2 - Disponível em:

http://graficadefronteira.files.wordpress.com/2009/02/catalogo-rico-lins-projetosgraficos-comentados.pdf Acesso em: 07/07/12

Figura 3 - Disponível em:

http://uploads0.wikipaintings.org/images/alexander-rodchenko/books-1924.jpg Acesso em: 07/07/12

Figura 4 - Disponível em:

http://issuu.com/ricolins/docs/caixagrafica\#download Acesso em: 09/07/12

Figura 5 - Disponível em:

http://uploads0.wikipaintings.org/images/robert-rauschenberg/signs-1970.jpg Acesso em: 11/07/12

Figura 6 - Disponível em:

http://issuu.com/ricolins/docs/caixagrafica\#download Acesso em: 09/07/12

Figura 7 - Disponível em:

http://sdrc.lib.uiowa.edu/dada/merz/1/pages/00cover.htm Acesso em: 27/07/12 